\title{
Angular Cheilitis in Elderly Patient with Diabetes Mellitus and Decrease of Vertical Dimensions
}

\author{
Rahmi, Ayu Fresno Argadianti, Desiana Radithia and Bagus Soebadi \\ Department of Oral Medicine, Faculty of Dental Medicine, Universitas Airlangga, Surabaya, Indonesia
}

\begin{abstract}
Our patient is a 61-year-old, male, heavy smoker, and diagnosed with diabetes mellitus (DM) who sought medical intervention due to complaints of painful lesions on the left and right corners of the mouth. The patient lost a lot of teeth, only two remained intact and has never used dentures. We present a case of angular cheilitis in an elderly patient with DM and a decrease of vertical dimensions. Clinical management includes anamnesis, clinical examination, treatment and elimination of predisposing factors through integrated multidisciplinary treatment.
\end{abstract}

Key Words: angular cheilitis, diabetes mellitus, vertical dimensions

\section{INTRODUCTION}

Oral health is an integral part of general health and a significant determining factor for an individual's quality of life. ${ }^{1,2}$ Oral health reflects overall well being for the elderly ${ }^{3}$ which is defined in the Indonesian minister of health regulation number 79 of 2014, as someone who has reached the age of sixty and above. ${ }^{4}$ There are substantial changes in immunity as age increases and these changes will contribute to occurrence of infections and inflammation diseases. ${ }^{5}$

Angular cheilitis presents as an inflammation at the corner of the mouth that affects between $0.7 \%$ and $3.8 \%$ of the general population, occurring most frequently in children (ages 0-18), and then again in adults (ages 30 to 60). There is a three-fold incidence in patients using dentures. ${ }^{6}$ Our patient who has lost most of his teeth due to old age has never used dentures yet acquired a rare case of angular cheilitis with other local and systemic conditions such as diabetes mellitus (DM) and decrease of vertical dimensions.

Maintaining the oral health of elderly patients is vital due to its correlation to nutrition and their relationship to systemic infection. ${ }^{3}$ Elderly patients with underlying systemic and local factors need interdisciplinary management because there is no complete and comprehensive cure if only local or systemic factors are managed.

We present a rare case of angular cheilitis in elderly patient with no history of dental dentures, diagnosed with $\mathrm{DM}$ and has a decrease of vertical dimensions accompanied by other underlying predisposing factors.

Dentistry, July 5, 2019, Amerta Room, 4th Floor, main campus of Universitas Airlangga, Surabaya, Indonesia

Corresponding author: Desiana Radithia

Department of Oral Medicine

CASE REPORT

Faculty of Dental Medicine

Universitas Airlangga

Jl. Mayjen. Prof. Dr. Moestopo No. 47 Surabaya 60132 - Indonesia

Email: deisy.radithia@fkg.unair.ac.id

A 61-year-old male, Javanese and married, came to the Dental and Oral Hospital of Universitas Airlangga as an outpatient, with chief complaints of pain in the corners of the 

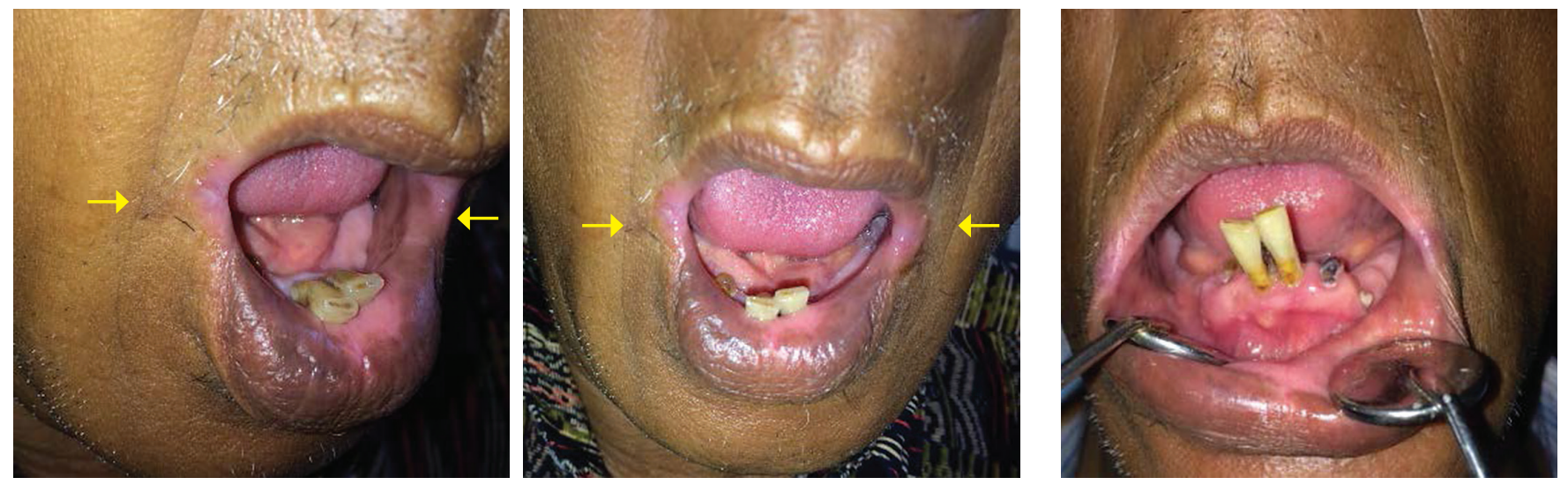

Figure 1. Erythematous fissure in the right and left corner of the mouth at the first visit.

Figure 2. Condition of the patient's teeth.
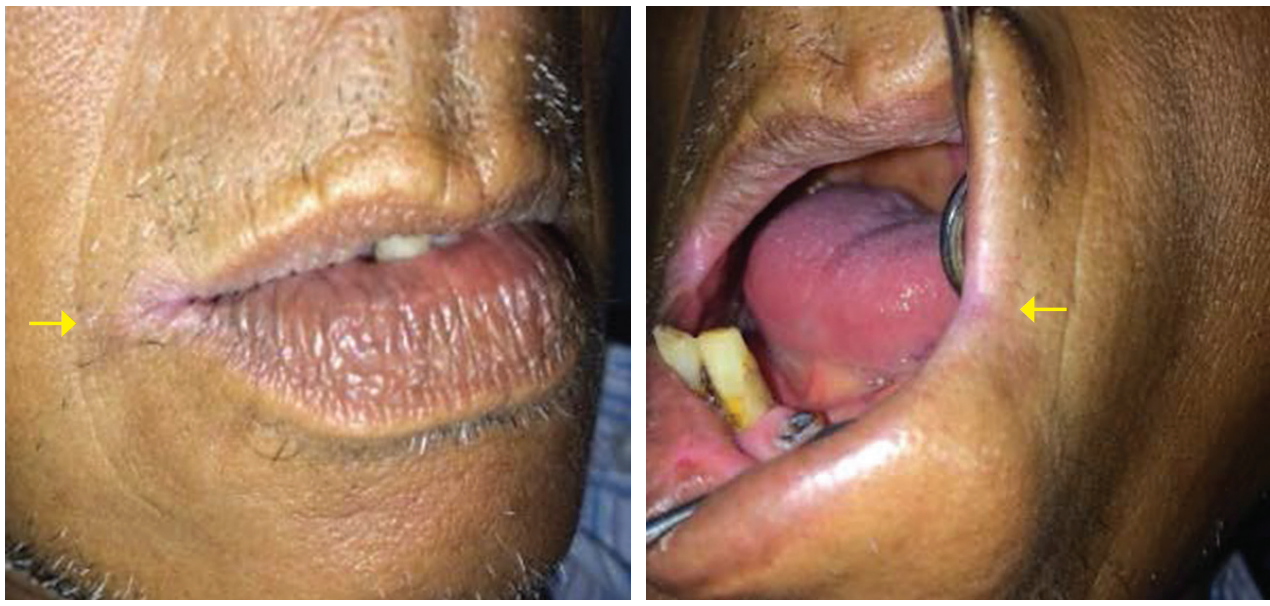

Figure 3. During the second visit, shows erythematous erosion in both corners of the mouth.

left and right mouth and sometimes bleeding spontaneously three days prior to the consultation. There are no prodromal symptoms before the lesion came and no allergy history from patient. The patient had never been to a doctor to treat the complaint. The patient is diagnosed to have DM three years ago and usually takes glibenclamide twice a day along with metformin $\mathrm{HCl} 500 \mathrm{mg}$ twice a day. The last time the patient went to a general practitioner was for fasting blood glucose (FBS) test five months ago and the reading was $279 \mathrm{mg} / \mathrm{dL}$ FBS level. Patient has lost most of his teeth and only two remain intact however has no history of using dentures. Patient has also been smoking for decades and usually consumes three packs a day. Extraoral examination on the right and left corner of the mouth found fissure lesions with irregular edges of erythema, clearly defined and painful (Figure 1). Intraoral examinations found pseudomembran on dorsal of tongue with diffuse borders, irregular edges, yellowish-white surface that can be scraped and painless. Area of edentulous includes maxilla and for mandible only 31, 41 and gangrene radix of 33 and 43 left. (Figure 2). With these conditions, the patient had a decrease in vertical dimension because there's no space for occlusion between the upper and lower teeth.
Working diagnosis for this case was angular cheilitis. Herpeticlesion, syphilitic papula,local trauma, and malignancy as differential diagnosis. Examination of sialometry, complete blood count, random blood sugar, and fasting blood sugar tests were also done. Sialometry examination result was $0 \mathrm{ml}$ / min of saliva. Treatment management done on our patient includes asepsis with $10 \%$ of povidone-iodine and chlorine dioxide dental gel as topical anti-inflammatory drugs and was prescribed chlorine dioxide dental gel to be applied four times a day. Discharge instructions such as to use the gel regularly, maintain oral hygiene, increase consumption of fruits, vegetables, water and stop smoking habits were also given.

Patient came back for a second visit four days after the first visit and reports $0 / 10$ pain although the prescribed medications were not taken as ordered. From the extraoral examination, lesion on the right and left lip corner of the mouth has erosion with clear borders, irregular edges, redness, and painless (Figure 3). Laboratory results showed erythrocyte sedimentation rate is $43-78 \mathrm{~mm} /$ hour (high) ( $\mathrm{n}=<15 \mathrm{~mm} /$ hour), lymphocytes is $53 \%$ (high) ( $\mathrm{n}=25 \%-$ $33 \%$ ), fasting blood glucose level is $154 \mathrm{mg} / \mathrm{dl}$ (high) $(\mathrm{n}=70-115 \mathrm{mg} / \mathrm{dl})$ and random blood glucose level is 238 

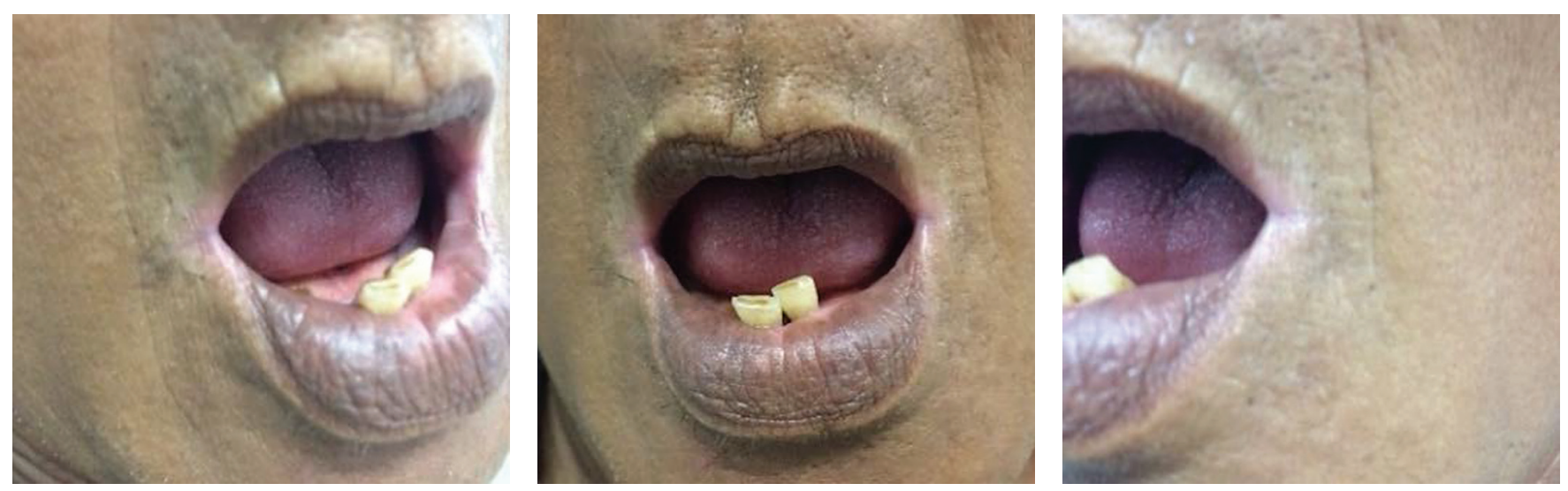

Figure 4. Hypopigmented macules during the third visit.

$\mathrm{mg} / \mathrm{dl}$ (high) ( $\mathrm{n}=<200 \mathrm{mg} / \mathrm{dl})$. During the third visit, lesions on both corners of the mouth have healed and patient reports no pain and discomfort although the patient did not comply with the prescribed topical medication. On clinical examination, the lesions are now hypopigmented macules with diffuse borders, irregular edges, and painless. (Figure 4). Eventually, the final diagnosis of this case is angular cheilitis. The lesions on the left and right corners of the mouth ruled out the herpetic lesion nor syphilitic papula, and local trauma which lesions are commonly unilateral. Healing of the lesion after treatment also ruled out the possibility of malignancy. At the end of visit, patient was referred to internist for the DM condition, referred to oral and maxillofacial surgery clinic to remove gangrene radix, and referred to periodontology clinic for scaling and root planing of remaining teeth as well as to the prosthodontics clinic for dentures.

\section{DISCUSSION}

A patient's age is a major factor to be considered especially in a case like angular cheilitis with DM. As age increases, substantial changes in immunity will occur. These changes will greatly contribute to the occurrence of infectious and inflammatory diseases. ${ }^{5}$ Angular cheilitis is characterized by painful fissure, inflammation on one or both corners of the mouth, and typically presents as erythema, scaling, fissuring, and ulceration. ${ }^{7,8}$ If all the teeth in the maxilla are lost, vertical dimensions will decrease because of the absence of occlusion between upper and lower teeth. The combination of bone resorption, muscle atrophy, and tooth loss will cause a reduction in the distance between the nose and chin. This condition causes the skin around the mouth area to fold and wrinkle. The presence of folds and wrinkles will accommodate saliva in which the presence of C. albicans and other contaminants causes a bacterial or viral infection. ${ }^{7,8,9}$

Poor oral hygiene, old age, and smoking habits are the main contributing factors to our patient's loss of teeth and only two teeth remain intact with some gangrene radix left. Further examination reveals gingivitis with the presence of calculus. Periodontal disease is one of the etiology factors that greatly contribute to tooth loss in the elderly. ${ }^{10}$ Epidemiological studies have linked DM and periodontal disease mostly due to a decrease in glycemic control in patients with DM..$^{11,12}$ Several studies also show the significant effect of smoking habits and age factors in tooth loss, where an aging smoker will have a higher chance of losing teeth compared to non-smokers. ${ }^{10,13}$ Loss of a lot of teeth finally decrease patient's vertical dimension and resulting in accumulation of the saliva on the corner of mouth. Sialometry procedure results showed patient has xerostomia or dry mouth, a condition that affects almost $50 \%$ of the elderly in which salivation decreases with age. ${ }^{14}$ Moreover, xerostomia contributes around $5 \%$ as a risk factor for angular cheilitis. Hyposalivation condition decreases oral clearance, salivary $\mathrm{pH}$, and buffer capacity. ${ }^{15}$

Other laboratory tests such as complete peripheral blood count test, mean corpuscular hemoglobin, $(\mathrm{MCH})$ and mean corpuscular hemoglobin concentration (MCHC) of the patient are normal but tend to be on the lower side. This result is probably caused by the patient's daily food patterns in which the patient rarely consumes fruits and vegetables. Lack of regular intake of vegetables and fruits reduces patient's absorption of vitamins and minerals such as iron, folic acid, and vitamin B12. ${ }^{16,17}$ Less substances of folic acid and vitamin B12 are also some of the predisposing factors of angular cheilitis. ${ }^{16,6}$

Management of the patient's condition includes local therapy with chlorine dioxide dental gel (oxyfresh $\left.{ }^{\circledR}\right)$. Chlorine dioxide is a powerful oxidizing and germicidal agent with the ability to eliminate a wide range of bacteria, viruses and fungi. ${ }^{18}$ Chlorine dioxide gel showed a positive response in the healing process of the mouth lesions. In addition, angular cheilitis can be secondary to candida infection. A culture swab on the corners of the mouth should be done if there is a poor response to the therapy. The culture swab was not done in our patient's case because 1) Patient's lesions 
were responsive with the chlorine dioxide dental gel and 2) other studies mention that angular cheilitis with candida infection is more common in elderly with dentures. ${ }^{19}$ The patient was then referred to an internist for management of DM. Patient was also referred to periodontist and oral maxillofacial surgery clinic for oral hygiene care.

\section{CONCLUSION}

Angular cheilitis in elderly patient with DM and decrease of vertical dimension can be treated by local therapy. But eldery patient with multiple underlying systemic and local factors need interdisciplinary management because the symptoms will only reoccur if local factors or systemic factors are not managed.

\section{Declaration of Patient Consent}

The authors certify that they have obtained all appropriate patient consent forms. In the form, the patient has given his consent for his images and other clinical information to be reported in the journal. The patient understands that their names and initials will not be published and due efforts will be made to conceal their identity, but anonymity cannot be guaranteed.

\section{Statement of Authorship}

All authors participated in data collection and analysis, and approved the final version submitted.

\section{Author Disclosure}

All authors declared no conflict of interest.

\section{Funding Source}

None.

\section{REFERENCES}

1. Lewis A, Wallace J, Deutsch A, King P. Improving the oral health of frail and functionally dependent elderly. Aust Dent J. 2015 Mar; 60 Suppl 1:95-105.

2. Baumgartner W, Schimmel M, Müller F. Oral health and dental care of elderly adults dependent on care. Swiss Dent J. 2015;125(4):417-26.

3. Gil-Montoya JA, de Mello AL, Barrios R, Gonzalez-Moles MA, Bravo M. Clinical Interventions in Aging Dovepress Oral health in the elderly patient and its impact on general well-being: a nonsystematic review. Clin Interv Aging. 2015 Feb; 10:461-7.
4. PMK RI No 79 tahun 2014. In 2014. p. 561-5. Available from: http:// bprs.kemkes.go.id/v1/uploads/pdffiles/peraturan/47 PMK No. 79 ttg Penyelenggaraan Pelayanan Geriatri di RS.pdf

5. Accardi $\mathrm{G}$, Caruso C. Immune-inflammatory responses in the elderly : an update. Immun Ageing. $2018 \mathrm{Mar}$; 15-:11.

6. Lorenzo-Pouso AI, García-García A, Pérez-Sayáns M. Hyaluronic acid dermal fillers in the management of recurrent angular cheilitis: A case report. Gerodontology. 2018 Jun; 35(2):151-4.

7. Ayesh MH. Angular cheilitis induced by iron defi ciency anemia. Cleve Clin J Med. 2018 Aug; 85(8):581-2.

8. Oza N, Doshi JJ. Angular cheilitis: A clinical and microbial study. Indian J Dent Res. 2017 Nov-Dec; 28(6):661-5.

9. Jafari AA, Lotfi-Kamran MH, Falah-Tafti A, Shirzadi S. Distribution profile of Candida species involved in angular cheilitis lesions before and after denture replacement. Jundishapur J Microbiol. 2013;6(6):1-4.

10. Natto ZS, Aladmawy M, Alasqah M, Papas A. Factors contributing to tooth loss among the elderly: A cross sectional study. Singapore Dent J. 2014 Dec; 35:17-22.

11. Liljestrand JM, Havulinna AS, Paju S, Männistö S, Salomaa V, Pussinen PJ. Missing teeth predict incident cardiovascular events, diabetes, and death.J Dent Res. 2015 Aug; 94(8):1055-62.

12. Quinterol OMS, Borrego AP, Fernandez YF, et al. Influence of Diabetes Mellitus on the oral health of the elderly. MOJ Gerontol Ger. 2017;2(3):241-4.

13. Borojevic T. Smoking and periodontal disease. Mater Sociomed. 2012; 24(4):274-6.

14. Dalodom S, Lam-ubol A, Jeanmaneechotechai S, Takamfoo L, Intachai W, Duangchada K, et al. Influence of oral moisturizing jelly as a saliva substitute for the relief of xerostomia in elderly patients with hypertension and diabetes mellitus. Geriatr Nurs (Minneap). 2016 Mar-Apr; 37(2):101-9.

15. Federico JR , Basehore BM, Zito PM. Angular Chelitis [Internet]. 2019 [cited 2019 May]. Available from: https://www.ncbi.nlm.nih. gov/books/NBK536929/.

16. Bhattacharya PT, Misra SR. Effects of Iron Deficiency on the Oropharyngeal Region: Signs, Symptoms, and Biological Changes. In: Preedy VR, Patel VB, eds. Handbook of Famine, Starvation, and Nutrient Deprivation. Springer International Publishing; 2017. pp.1-18.

17. Apriasari ML, Carabelly AN. Angular cheilitis and oral pigmentation as early detection of Peutz-Jeghers syndrome. Dent J (Majalah Kedokteran Gigi). 2018 Mar; 51(1):29-32.

18. Al-Bayaty F, Abdulla MA. A comparison of wound healing rate following treatment with aftamed and chlorine dioxide gels in streptozotocin-induced diabetic rats. Evid Based Complement Alternat Med. 2012; 2012:468764.

19. Rakhmayanthie N, Herawati E, Marhaeni D, Herawati D. Effect of nutritional intake towards angular cheilitis of orphanage children. Padjadjaran Journal of Dentistry. 2016; 28(3):164-70. 